\title{
Effect of grounded bone powder addition on the mechanical properties of cement mortar
}

\author{
M. Kotb ${ }^{1}$, M. Assas ${ }^{2}$ \& H. Abd-Elrahman ${ }^{1}$ \\ ${ }^{I}$ Civil Engineering Department, Al-Azhar University, Egypt \\ ${ }^{2}$ Civil Engineering Department, Umm Alqura University, Saudi Arabia
}

\begin{abstract}
This paper presents an experimental investigation on the effect of using bone powder (BP), as a cement addition, on the mechanical properties of cement mortar. The evaluation was based on the assessment of mechanical properties (compressive strength and indirect tensile strength) measured at 7, 28, 90, 180 and 270 days. The abrasion resistance was measured at 7 and 28 days. The BP was added by the percentages of $0,5,10$, and $15 \%$ (weight $\%$ of cement). A sand to cement ratio of $3: 1$ was used. The water/cement ratio was kept at 0.55 . The results of all tests showed high performance based on compressive strength, and tensile strength when adding 5\% BP to cement mortar. The addition of $10 \%$ or $15 \% \mathrm{BP}$ is not recommended for compressive and tensile property requirements, where the strength results record lower strength values compared to that of $0 \%$ BP. Although the abrasion resistance of the mortar specimen improved with the addition of BP up to $10 \%$ at the testing age of 7 days, the improvement was continued with the addition of $15 \% \mathrm{BP}$ at the testing age of 28 days. X-ray diffraction and a scanning electron microscope (SEM) were also invoked to show phase transformations and microstructure analysis due to the BP addition after hardening; the increase of strength at $5 \%$ bone powder (BP) is mainly due to the bone acting as a filler or nucleating agent, which accelerates the hydration of cement.
\end{abstract}

Keywords: bone powder, compressive strength, tensile strength, abrasion resistance, hardening. 


\section{Introduction}

Meat and bone meal (MBM) is a by-product of the food industry, obtained by the removal of fat from mammal carcasses by a process of crushing, cooking and grinding. In Europe, more than $3 \mathrm{M}$ tons of $\mathrm{MBM}$ are produced annually [9]. Before May 1st 2003, MBM was classified in Europe according to whether it came from sources defined as high risk or low risk. The high-risk source concerned principally the MBM obtained from animals infected by transmissible spongiform encephalopathy (TSE), animals that had died of natural or unknown causes, and specified risk materials (SRM), such as brains, eyes, tonsils and the spinal cords of bovine, ovine and caprice animals [4]. The low-risk source included MBM from healthy, non-infected animals intended for human consumption [6]. Since June 28th 1996 in France, all high-risk MBM are co-incinerated through specific channels, mainly in the cement industry, except for MBM coming from animals having TSE. The chemical, mineralogical, physical, and leaching characteristics of MBM obtained from one laboratory and one industrial process were compared in order to classify these wastes and evaluate possible ways of valorization [13] and to provide a technical and environmental assessment of its potential for use as a substitute for sand in cement-based materials [11].

Bone meal is a mixture of crushed and coarsely ground bones that is used as an organic fertilizer for plants and in animal feed. As a fertilizer, bone meal is primarily used as a source of phosphorus. Bone meal is used as a supplement for calcium and phosphorus. It is composed of finely crushed, processed bone, usually from cattle, but sometimes also from horses. Bone marrow may also be added to the product. Calcium in bone meal occurs as a calcium phosphate compound known as hydroxyapatite or hydroxylapatite. Hydroxyapatite is an inorganic compound found in the matrix of bone and the teeth; it confers rigidity to these structures. The formula of hydroxyapatite is $\left(\mathrm{Ca}_{3}(\mathrm{PO} 4)_{2}\right)_{3} \mathrm{Ca}(\mathrm{OH})_{2}$ or $\mathrm{Ca}_{10}\left(\mathrm{PO}_{4}\right)_{6}(\mathrm{OH})_{2}[14]$.

Recent references have pointed to opportunities for the development of adhesives and sound or thermal insulation from meat and bone meal $[5,7]$. The Fats and Proteins Research Foundation (FPRF) is initiating a project to explore the application of meat and bone meal in composite structures, such as concrete and asphalt materials and insulation for heat and sound [8].

For public health reasons, meat and bone meal can no longer be used as animal feed. A 1997 study conducted by France's public environmental agency ADEME concluded that the meal is destroyed in the $2000^{\circ} \mathrm{C}$ flame of a cement kiln, with no detrimental impact on the environment or public health. Moreover, using the meat and bone meal in the cement plant is as a substitute for fossil fuels has cut $\mathrm{CO}_{2}$ emissions and saved fossil energy resources, while providing an effective disposal solution for meat and bone meal. The use of meat and bone meal as animal feed is now prohibited in Japan, and an effective disposal solution had to be found. The combustion conditions of cement mill clinker kilns (temperature of $1450^{\circ} \mathrm{C}$ and long residence times) are suitable for the destruction of meat and bone meal under optimal safety conditions. Moreover, the meat and 
bone meal constitutes a significant source of energy, which can be tapped by using it as a substitute fuel [17].

Co-incineration in cement kilns is the most common way, for MBM destruction, used in France. They are mixed with cement compounds (calcium, silica, alumina, etc.) and heated over $1500^{\circ} \mathrm{C}$ to produce the clinker. In England, the use of MBM dedicated incinerator is developed. Incineration plants are set up in Glanford, Wyminton and Widnes with a joint capacity of 205,000 tons of MBM/year. In France, for example, 850,000 tons of MBM are produced each year but actually only $45 \%$ can be burned by cement plants [2].

The objective of this paper is to investigate the effect of incorporating bone powder on as an addition to cement in concrete industry. The evaluation was based on the computation of compressive, tensile strengths and abrasion resistance on mortar containing bone powders by different percentages as an addition of cement and comparing the results with the non-bone powder cement mortar at different testing ages.

\section{Materials and method}

The bone powder (BP) shown in Fig. 1 was obtained by crushing animal bones. The supplied bones were cleaned, boiled in water, and dried for several months to remove any organic materials. After that, they were suitable for crushing using water wheel - powered bone crusher as shown in Fig. 2 into a relatively dry gritty powder. The cement used was ordinary Portland cement (OPC) according to E.S. 373/199. The chemical composition and Physical properties of the used $\mathrm{BP}$ and OPC are respectively illustrated in Table 1 and Table 2. The results of setting time test on the cement paste specimens incorporating $0,5,10$, and $15 \%$ bone powder are given in Table 3 according to ECCS 203-2003 [10] and SBC 302-2007 [12]. The water-cement ratio required to give a paste of standard consistency was equal to 0.29 . Natural clean sand having specific gravity of 2.57 , compacted density of $1.79 \mathrm{t} / \mathrm{m}^{3}$ and fineness modulus of 2.49 was used in the fabrication of test specimens. Tap water has been used for mixing and curing works. The sand-cement ratio was kept equals to $3: 1$. The water cementitious ratio was 0.55 . The BP additions were $0,5,10$, and $15 \%$ by weight of cement.

The experimental program shown in Table 4, was designed to estimate the abrasion resistance (cylinders $25.4 \times 25.4 \mathrm{~mm}$ ) was estimated for all $\mathrm{BP}$ percentages at 7 and 28 days, the compressive ( cubes $70.7 \mathrm{~mm}$ side length) and tensile strengths (cylinders $75 \times 150 \mathrm{~mm}$ ) of mortar specimens having BP addition equals to $0 \%, 5 \%, 10 \%$ and $15 \%$. The moulds were greased and prepared for casting. Batch materials required for casting one batch were weighted first. Dry materials for this batch were mixed in the dry state for a time to insure the homogeneity of the mixture before adding the mixing water. Mortar was placed in moulds and then compacted on electrical vibrating table. The specimens were removed from moulds 24 after casting, marked, and then immersed in the curing water. The specimens were removed from the curing water one day before the test. 
The compression and tensile test specimens were tested on a universal hydraulic testing machine of capacity $1000 \mathrm{KN}$. according to ECCS 203-2003 [10] and SBC 302-2007 [12]. The revolving disk (ASTM C779, Procedure A) test method [1] was used for the completion of wear test. An aggregate abrasiontesting machine (Cat. No. EL 42-500) was used to perform the test. The test specimens were exposed to abrasive standard sand, passed from $0.6 \mathrm{~mm}$ sieve, and retained on $0.45 \mathrm{~mm}$ sieve, for 500 revolutions under a load of $750 \mathrm{gm}$. Each specimen was weighted before and after the test and the weight, loss was recorded. The abrasive wear rate is thus defined as the weight loss of the tested specimen divided by the area of the surface exposed to wear. This is of a physical meaning, since abrasion is a surface property that defines surface layer characteristics. The exposed surface area for all specimens is constant and equal to the area of a circle having a diameter of $25 \mathrm{~mm}$. The abrasive wear rate unit is $\mathrm{gm} / \mathrm{cm}^{2}$. The wear test was preformed at 7 and 28 days.

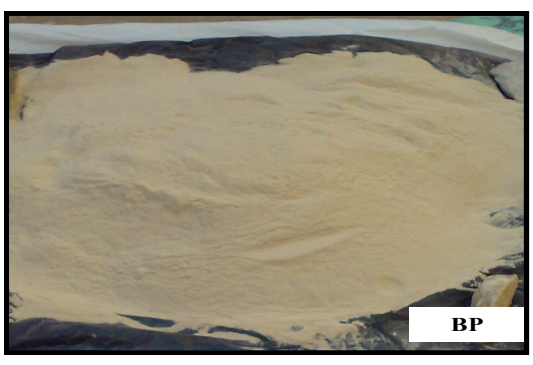

Figure 1: $\quad$ Bone powder.

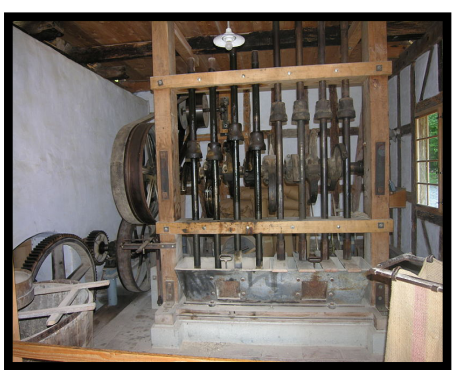

Figure 2: $\quad$ Water wheel BP crusher.

Table 1: $\quad$ Chemical composition (wt $\%)$ of BP and OPC.

\begin{tabular}{|c|c|c|}
\hline Oxides & BP & OPC \\
\hline $\mathrm{CaO}$ & 52.45 & 62 \\
\hline $\mathrm{SiO}_{2}$ & 1.34 & 20.39 \\
\hline $\mathrm{Al}_{2} \mathrm{O}_{3}$ & 0.35 & 5.05 \\
\hline $\mathrm{Fe}_{2} \mathrm{O} 3$ & 0.25 & 2.89 \\
\hline $\mathrm{MgO}$ & 1.3 & 2.07 \\
\hline $\mathrm{K}_{2} \mathrm{O}$ & 0.3 & 0.5 \\
\hline $\mathrm{Na}_{2} \mathrm{O}$ & 1.6 & 0.07 \\
\hline $\mathrm{SO}_{3}$ & 0.41 & 2.4 \\
\hline $\mathrm{MnO}$ & $<0.03$ & - \\
\hline $\mathrm{P}_{2} \mathrm{O}_{5}$ & 36.85 & - \\
\hline $\mathrm{TiO}_{2}$ & $<0.01$ & \\
\hline $\mathrm{Cl}^{-}$ & 0.4 & \\
\hline Others & 4.71 & 1.53 \\
\hline L.O.I & 1.2 & 3.1 \\
\hline
\end{tabular}


Table 2: $\quad$ Physical properties of OPC and BP.

\begin{tabular}{|l|l|l|l|l|}
\hline \multirow{2}{*}{ BP \% } & \multicolumn{4}{|l|}{ Setting time, Vicat apparatus } \\
\cline { 2 - 5 } & Initial & Final \\
\cline { 2 - 5 } & Hour & Minute & Hour & Minute \\
\hline 0 & 01 & 42 & 05 & - \\
\hline 5 & - & 54 & 03 & 43 \\
\hline 10 & 01 & 02 & 4 & 14 \\
\hline 15 & 01 & 11 & 06 & 29 \\
\hline
\end{tabular}

Table 3: $\quad$ Setting time for cement paste with and without B.

\begin{tabular}{|l|l|l|}
\hline Properties & OPC & BP \\
\hline Specific gravity & 3.15 & 1.85 \\
\hline Density, t/m3 & 1.05 & 0.690 \\
\hline $\begin{array}{l}\text { Fineness (\%wt retained on sieve } \\
\text { No 170) }\end{array}$ & 8 & 7 \\
\hline Colour & Gray & $\begin{array}{l}\text { Light } \\
\text { yellow }\end{array}$ \\
\hline
\end{tabular}

Table 4: $\quad$ Experimental program suggested for the present work.

\begin{tabular}{|c|c|c|c|c|c|c|c|c|c|c|c|c|c|c|c|c|c|}
\hline \multirow[b]{2}{*}{$\begin{array}{l}\ddot{\Xi} \\
0 \\
. 凶 \\
\Sigma\end{array}$} & \multirow{2}{*}{ 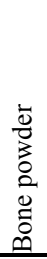 } & \multirow[b]{2}{*}{ 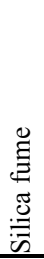 } & \multirow{2}{*}{ 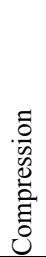 } & \multirow[b]{2}{*}{ 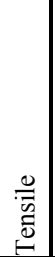 } & \multirow[b]{2}{*}{ 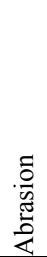 } & \multicolumn{5}{|c|}{$\begin{array}{l}\text { Cubes } \\
70 \times 70 \times 70 \mathrm{~mm}\end{array}$} & \multicolumn{5}{|c|}{$\begin{array}{l}\text { Cylinders } \\
75 \times 15 \mathrm{~mm}\end{array}$} & \multicolumn{2}{|c|}{ 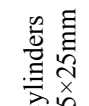 } \\
\hline & & & & & & $\sum_{\substack{i \\
i}}^{n}$ & 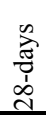 & 疍 & 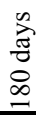 & 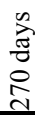 & $\sum_{\substack{i \\
i}}^{n}$ & 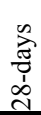 & 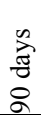 & 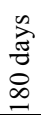 & 疍 & 额 & 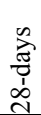 \\
\hline \multirow{3}{*}{$\begin{array}{l}\text { MB } \\
0\end{array}$} & \multirow{3}{*}{$\begin{array}{l}0 \\
\%\end{array}$} & & & & & 3 & 3 & 3 & 3 & 3 & & & & & & & \\
\hline & & - & & & & & & & & & 3 & 3 & 3 & 3 & 3 & & \\
\hline & & & & & & & & & & & & & & & & 3 & 3 \\
\hline \multirow{3}{*}{$\begin{array}{l}\mathrm{MB} \\
5\end{array}$} & \multirow{3}{*}{$\begin{array}{l}5 \\
\%\end{array}$} & \multirow{3}{*}{-} & & & & 3 & 3 & 3 & 3 & 3 & & & & & & & \\
\hline & & & & & & & & & & & 3 & 3 & 3 & 3 & 3 & & \\
\hline & & & & & & & & & & & & & & & & 3 & 3 \\
\hline \multirow{3}{*}{$\begin{array}{l}\text { MB } \\
10\end{array}$} & \multirow{3}{*}{$\begin{array}{l}10 \\
\%\end{array}$} & \multirow{3}{*}{-} & & & & 3 & 3 & 3 & 3 & 3 & & & & & & & \\
\hline & & & & & & & & & & & 3 & 3 & 3 & 3 & 3 & & \\
\hline & & & & & & & & & & & & & & & & 3 & 3 \\
\hline \multirow{3}{*}{$\begin{array}{l}\text { MB } \\
15\end{array}$} & \multirow{3}{*}{$\begin{array}{l}15 \\
\%\end{array}$} & & & & & 3 & 3 & 3 & 3 & 3 & & & & & & & \\
\hline & & - & & & & & & & & & 3 & 3 & 3 & 3 & 3 & & \\
\hline & & & & & & & & & & & & & & & & 3 & 3 \\
\hline \multicolumn{6}{|c|}{ Total } & \multicolumn{5}{|c|}{60} & & \multicolumn{3}{|l|}{60} & & \multicolumn{2}{|c|}{24} \\
\hline
\end{tabular}

\section{Results and discussions}

\subsection{Compressive strengths}

The compressive strength for cement mortar incorporating grounded bone powder is shown in Fig. 3. The bone powder additions were 0, 5, 10 and $15 \%$ by weight of cement and. The mortar compressive strength was measured at ages of 


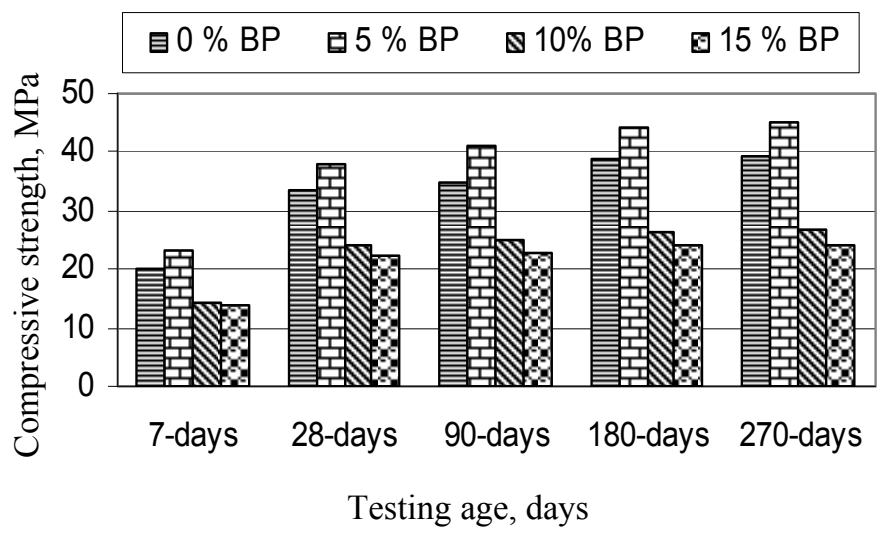

Figure 3: Effect of bone powder addition on the compressive strength of cement mortar.

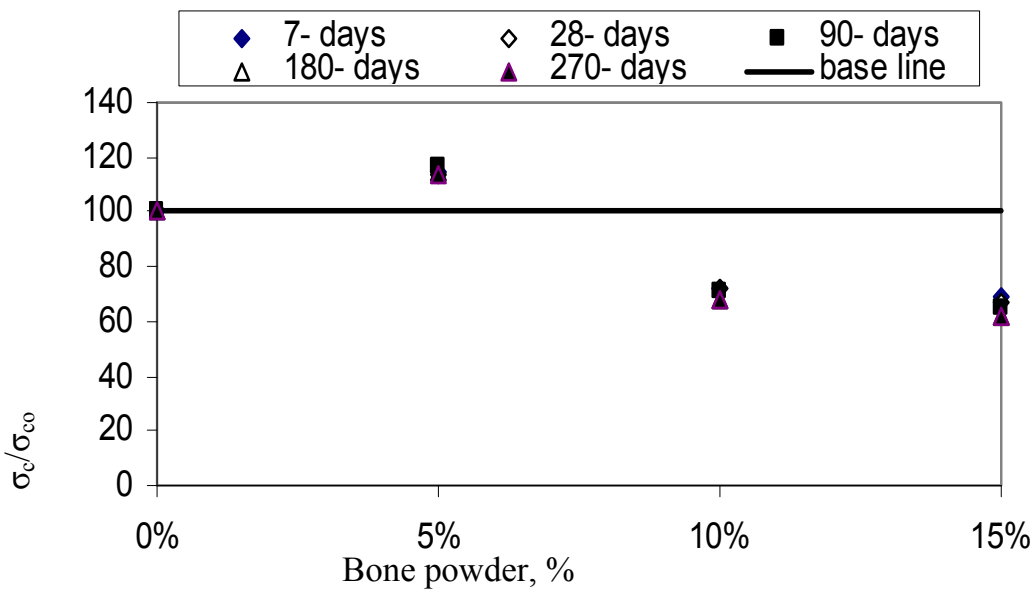

Figure 4: Effect of bone powder addition on the compressive strength ratio of mortar.

$7,28,90,180$, and 270 days. It is clear that the compressive strength increases as bone powder addition increases up to $5 \%$ beyond this, the compressive strength of mortar with 10 and $15 \%$ BP is lower than that of $0 \%$ BP. Fig. 4 reflects the effect of BP percentages $(0 \%, 5 \%, 10 \%$ and $15 \%)$ on the compressive strength ratio $\left(\sigma_{\mathrm{c}} / \sigma_{\mathrm{co}}\right)$ of cement mortar. Here $\sigma_{\mathrm{c}}$ is the compressive strength of mortar with $\mathrm{BP}$ while $\sigma_{\mathrm{co}}$ is the compressive strength of mortar specimens with $0 \% \mathrm{BP}$. The compressive strength ratio is about $115.2 \%$ with the addition of $5 \% \mathrm{BP}$, while it decreased to reach $72 \%$ with increasing $\mathrm{BP}$ addition to $10 \%$ and 


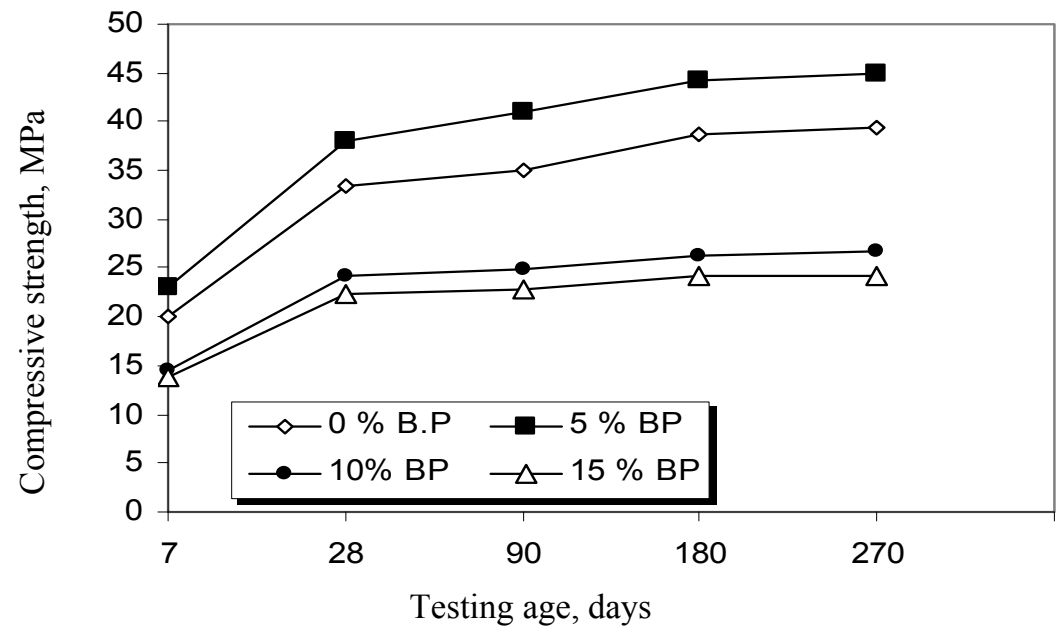

Figure 5: Effect of testing age on the compressive strength of mortar with or without BP.

decreased to $67 \%$ with increasing BP addition to $15 \%$. The effect of testing age on the compressive strength of mortar incorporating BP as an addition to cement is shown in Fig. 5. The figure shows an increase in the compressive strength for all mixes with increasing age. The rate of enhancement is decreased with increasing testing age. The ratio of 28 days compressive strength to that measured at 7 days is about $165 \%$ for all mixes containing either BP. This is due to the continuous hydration of cement during this period. The ratio of 28 days compressive strength to that measured at 90,180 and 270 days is about $105 \%$, $112.6 \%$ and $114.5 \%$ respectively for all mixes containing BP.

\subsection{Tensile strengths}

The effect of BP addition by $5 \%, 10 \%$, and $15 \%$ on the tensile strength of mortar is shown in Fig. 6. The results presented in the figure are for ages of 7, 28, 90, 180 and 270 days. It is clear that the tensile strength increases at BP of 5\%. Beyond this, the tensile strength of mortar with 10 and $15 \%$ BP is lower than that of $0 \% \mathrm{BP}$.

The effect of BP percentages $(0 \%, 5 \%, 10 \%$, and $15 \%)$ on the splitting tensile strength ratio $(\sigma t / \sigma t o)$ of cement mortar is shown in Fig. 7. Here $\sigma \mathrm{t}$ is the tensile strength of mortar mixes with BP addition while $\sigma$ to is the tensile strength of mortar specimens with $0 \%$ BP. The tensile strength ratio is about $125.6 \%$ with the addition of $5 \% \mathrm{BP}$, while it decreases to reach $90.5 \%$ with increasing BP addition to $10 \%$ and to $79.3 \%$ with increasing BP addition to $15 \%$.

The effect of testing age on the tensile strength of mortar incorporating BP as an addition to cement is shown in Fig. 8. The figure shows an increase in the 


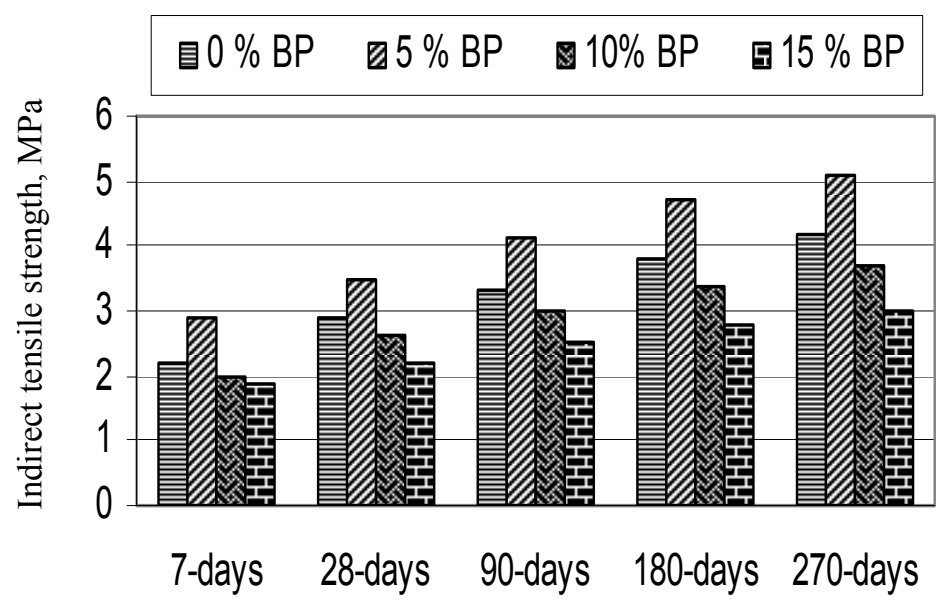

Testing age, days

Figure 6: Effect of bone powder addition on the indirect tensile strength of mortar.

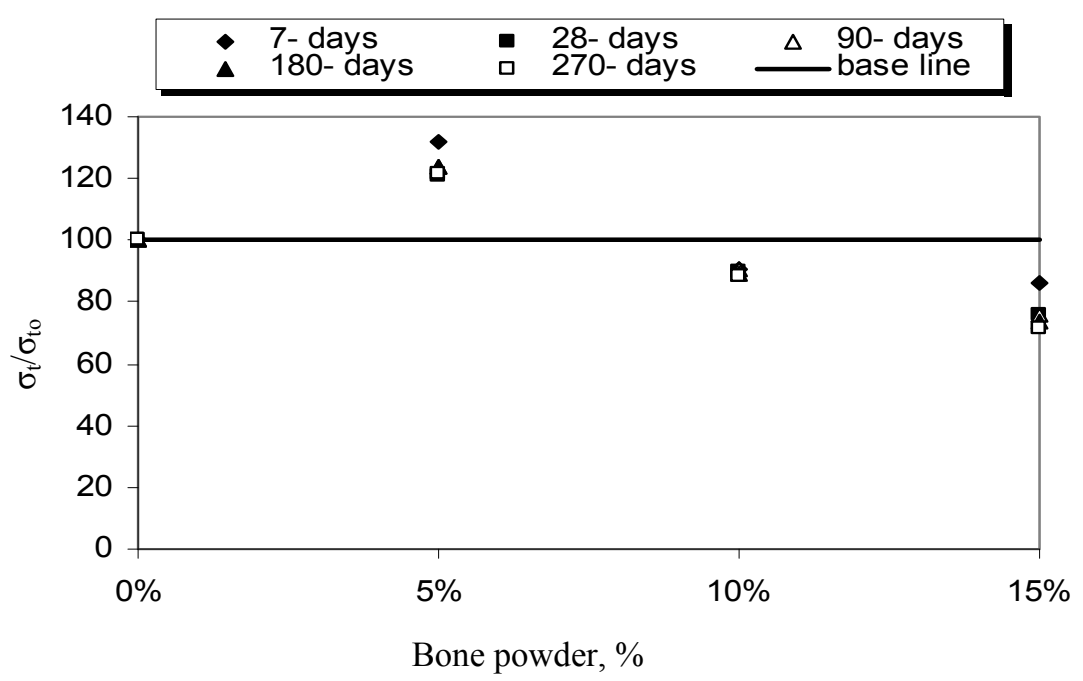

Figure 7: Effect of bone powder addition on the indirect tensile strength ratio of mortar. 


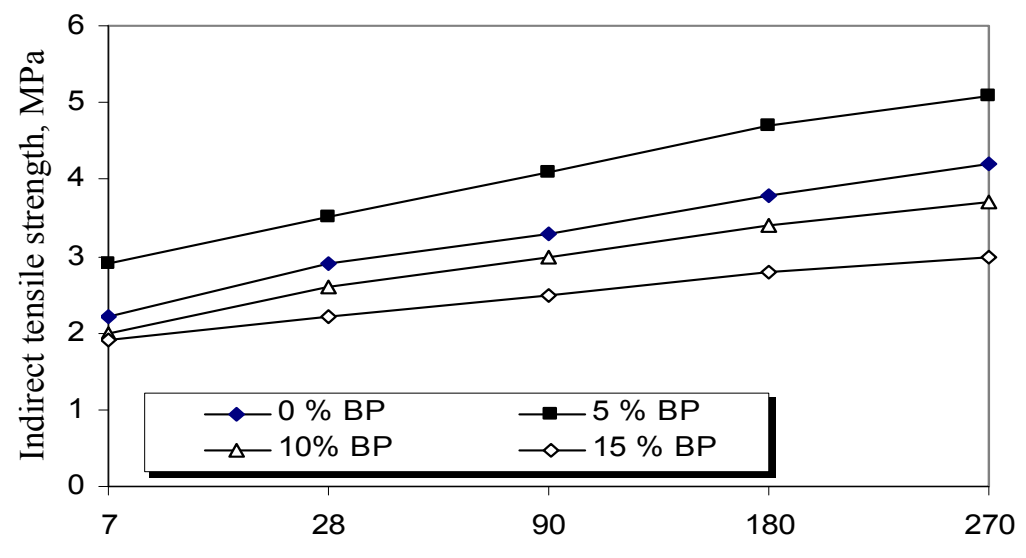

Age, days

Figure 8: Effect of testing age on the indirect tensile strength of mortar incorporating $\mathrm{BP}$ as an addition to cement.

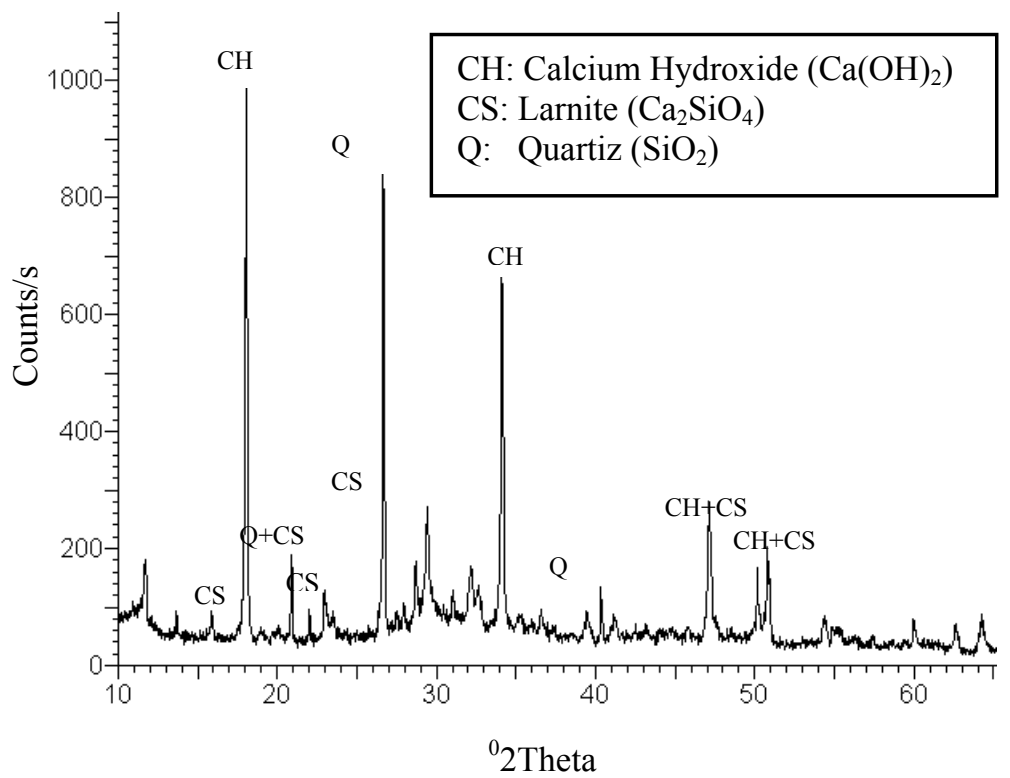

Figure 9: $\quad \mathrm{X}$-ray diffraction for cement mortar with $\mathrm{BP}=0 \%$. 
tensile strength for all mixes with increasing age. The rate of enhancement decreases with increasing the testing age. The ratio of 28 days compressive strength to that measured at 7 days is about $124.5 \%$ as an average for all mixes containing BP. The ratio of 28 days indirect tensile strength to that measured at 90,180 and 270 days is about $115.4 \%, 132 \%$ and $142.9 \%$ respectively for all mixes containing BP.

The improvement in the compressive and tensile strengths due to BP addition of $5 \%$ may be due to that the setting of cement with BP addition that contains calcium phosphate cement is essentially a dissolution precipitation reaction. It is controlled by the particle size of the reactants: finer particles will dissolve faster than the coarser ones. Thus, initial porosity is less in the mix containing bone powder, and the setting reaction operates on a shorter length scale. The resulting mix is denser with fewer and smaller pores and thus stronger. With the further addition in BP, the quantity of cement/ total aggregate ratio in the mix decreased which leads to a decrease in the measured strengths [3].

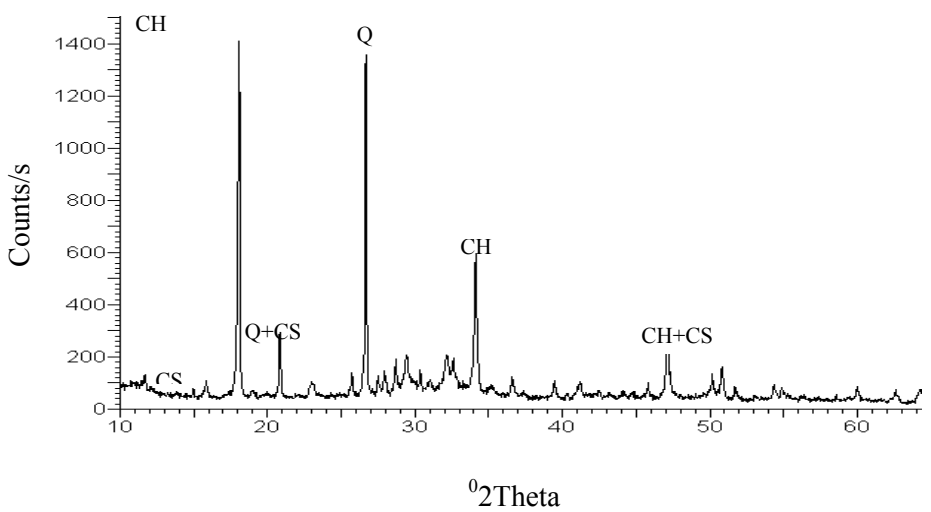

Figure 10: $\quad \mathrm{X}$-ray diffraction for cement mortar with $\mathrm{BP}=5 \%$.

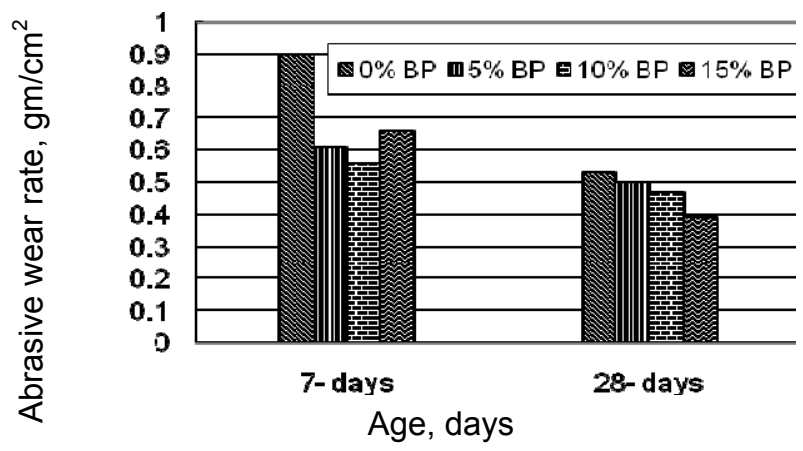

Figure 11: Effect of bone powder addition on the abrasive wear rate of mortar with or without BP addition. 
Figures 9 and 10 shows the x-ray diffraction patterns of cement mortar samples after they were immersed in clean water for 28 days. The Figure of plain cement mortar specimens (BP, 0\%), Fig.9, indicate high peaks of $\mathrm{CH}$ at ${ }^{\circ} 2 \mathrm{Theta}$ equal to 18 and 34. This $\mathrm{CH}$ was resulted from cement hydration. In the case of BP (5\%) addition, Fig.10 show higher peaks compared to those at $0 \% \mathrm{BP}$ addition. This is because; BP behaves filler (fills the voids in the matrix) and has not a pozzolanic effect. Thus, the increase in mortar strength due 5\% BP addition can be attributed to its physical effect in filling the voids in the matrix.

\subsection{Abrasion resistance}

The effect of BP addition on the abrasive wear rate at 7 and 28 days is illustrated in Fig. 11. The figure shows that at 7 days, the abrasive wear rate decreases (enhancement in the abrasion resistance) as the $\mathrm{BP} \%$ increases up to $10 \% \mathrm{BP}$ addition and after that it increases (lack in the abrasion resistance). At 28 days, the situation is a decrease in the abrasive wear rate with increasing BP up to $15 \%$, which means an enhancement in the abrasion resistance of the BP mortar. The figure also shows that the abrasive wear rate decreases with increasing age. These results indicate superior effect of BP addition on the enhancement of the abrasion resistance of mortar. This was expected because the abrasion resistance partly depends on the bond strength between contents of mortars, which increases with increasing BP content. An increase in the BP up to $15 \%$ resulted in improved surface characteristics and thus abrasion resistance.

\section{Conclusions}

The results of the present work on the utilization of bone powder in cementbased materials supported the following conclusions:

1. The compressive strength and tensile strength of bone cement mortar at ages of $7,28,90,180$, and 270 days increases as bone powder ratios increases up to $5 \%$ beyond this percent it decreases.

2. The mechanical properties of mortars mixes containing $5 \%$ of bone powder showed higher performance compared to $0 \%, 10 \%$, and $15 \%$ of bone powder.

3. The increase of strength at $5 \%$ bone powder (BP) is mainly due to that the bone acts as filler or nucleating agent, which accelerates the hydration of cement.

4. The abrasion resistance of mortar specimen improved by the addition of bone powder up to $10 \%$ at testing age of 7 days. The improvement was continued with the addition of $15 \%$ pone powder at testing age of 28 days.

\section{References}

[1] American Society for Testing and Materials, "Test method for abrasion resistance of horizontal concrete surfaces," ASTM C779-89, Annual Book of ASTM Standard, ASTM, 4.02, p 359 (1989). 
[2] European Council Directive 90/667/EEC of 27 November 1990, "laying down the veterinary rules for the disposal and processing of animal waste", Official Journal of the European Union, L 363, pp. 51-60, 1990 .

[3] B. B. Sabir, "High-Strength Condensed Silica Fume Concrete," Mag. Concr. Res., Vol. 47(1), pp. 219-226 (1995).

[4] European Commission Decision 2000/418/EC of 29 June 2000, "Regulating the Use of Material Presenting Risks As Regards Transmissible Spongiform Encephalopathies", Official Journal of the European Union, L 158, Vol. 43, pp. 76-82 (2000).

[5] Hettiarachchy, JOPCS 77 (November): 1223-1227, NS. 2000.

[6] European Regulation (EC) No 1774/2002 of the European Parliament and of the Council of 3 October 2002," Laying Down Health Rules Concerning Animal By-Products Not Intended For Human Consumption", Official Journal of the European Union, L 273, vol. 45, pp. 1-95 (2002).

[7] Thomsen, R., "Patent \#DE 20101411," Germany: 8, July 2002.

[8] Steenheuer, C., and Hobohn, F., "Patent \#DE10065095", Germany, July 2002.

[9] David Byrne, Official Journal of the European Union, C192E 46 (2003) 188, (14/08/2003 http://europa.eu.int/eur-lex/en/archive/2003/ ce19220030814en. html).

[10] The Egyptian code for concrete structural (ECCS 203-2003).

[11] Martin Cyr, Christine Ludmann, "Low risk meat and bone meal (MBM) bottom ash in mortars as sand replacement" Cement \& Concrete Research, Vol. 36, pp.469 - 480 (2006).

[12] The Saudi building code for structural tests and inspections (SBC 3022007).

[13] Marie Coutand, Martin Cyr, Eric Deydier, Richard Guilet, Pierre Clastres, "Characteristics of industrial and laboratory meat and bone meal ashes and their potential applications" Journal of Hazardous Materials, Vol. 150, pp. 522-532 (2008).

[14] http://www.fhwa.dot.gov/pavement/rcemicro.htm, "Microsilica-Utilization of Recycled Materials in Illinois Highway Construction."

[15] ASTMC 1240-97:"Standard Specification for Silica Fume for Use as a Mineral Admixture in Hydraulic Cement Concrete, Mortar, and Grout." 